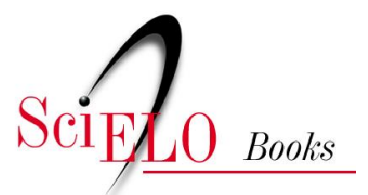

\title{
Democracia(s) em debate \\ novos discursos democráticos nos países andinos
}

\author{
Fabricio Pereira da Silva
}

\section{SciELO Books / SciELO Livros / SciELO Libros}

SILVA, FP. Democracia(s) em debate: novos discursos democráticos nos países andinos. In OLIVEIRA, RP., NOGUEIRA, SG., and MELO, FR., orgs. América Andina: integração regional, segurança e outros olhares [online]. Campina Grande: EDUEPB, 2012. pp. 255-274. ISBN 978-857879-185-8. Available from SciELO Books <http://books.scielo.org $>$.

\section{(1)(0)}

All the contents of this work, except where otherwise noted, is licensed under a Creative Commons Attribution-Non Commercial-ShareAlike 3.0 Unported.

Todo o conteúdo deste trabalho, exceto quando houver ressalva, é publicado sob a licença Creative Commons Atribuição Uso Não Comercial - Partilha nos Mesmos Termos 3.0 Não adaptada.

Todo el contenido de esta obra, excepto donde se indique lo contrario, está bajo licencia de la licencia Creative Commons Reconocimento-NoComercial-CompartirIgual 3.0 Unported. 
Parte III

Temas Específicos 



\section{Democracia(s) em debate: novos discursos democráticos nos países andinos}

Fabricio Pereira da Silva

\section{Resumo}

O artigo analisa concepções democráticas expressadas nos processos de refundação levados adiante na Venezuela, Bolívia e Equador. Procura primeiramente destacar contradições e transformações temporais em cada caso (apontando também novas instituições democráticas participativas desenhadas naqueles países a partir das referidas concepções). No final, apresenta sugestões para uma comparação entre os casos.

\section{Abstract}

This paper examines some concepts about democracy presented in the processes of "re-foundation" carried forward in Venezuela, Bolivia and Ecuador. First, highlights some contradictions and transformations in each case (and presents 
new participative democratic institutions in these countries designed according to these concepts). At the end, proposes suggestions for a comparative analysis between the cases.

\section{Introdução}

Esse artigo aborda concepções democráticas dos novos governos da Venezuela, Bolívia e Equador, onde movimentos de "refundação" das instituições estatais e da política de maneira geral canalizaram o descontentamento popular, chegando ao poder com apoio majoritário (PEREIRA DA SILVA, 2011). Para isso, serão avaliados quais aspectos da democracia têm sido criticados e fomentados nos processos transformadores analisados. Além disso, serão apontadas eventuais transformações discursivas ao longo do desenvolvimento desses novos governos.

A seguir, apresento algumas evidências discursivas como forma de ajudar a construir as visões de democracia majoritárias que circulam nos referidos processos refundadores, caso a caso. Adicionalmente, aponto em cada caso as instituições participativas desenvolvidas a partir de tais visões ${ }^{1}$. Ao final,

1 Não tratarei aqui dos mecanismos de democracia direta introduzidos por esses regimes, basicamente referendos para revogação e ratificação de leis constitucionais, bem como de decisões relativas à política externa (nos três países, qualquer modificação constitucional deve ser ratificada, assim como decisões transcendentes relacionadas à perda de soberania nacional para organismos internacionais); revogação de todos os cargos eletivos; iniciativa de lei popular, e inclusive de convocação de assembleia constituinte. Exemplos disso são as ratificações das convocações de assembleias constituintes nesses países, e a posterior aprovação popular 
lanço sugestões para a realização de um exercício comparativo. Parto do pressuposto de que os discursos e conceitos são sínteses em constante rearrumação das desiguais e cambiantes correlações de forças entre os líderes dos processos refundadores, os partidos e organizações sociais que os apoiam, bem como as disputas com setores oposicionistas. Como em qualquer movimento complexo, há diversas concepções em disputa, e versões minoritárias sempre presentes. Evidentemente, a gênese e as disputas entre essas concepções não poderão ser analisadas ou sequer "mapeadas" em profundidade nessas páginas. A função desse artigo é eminentemente realizar uma primeira abordagem sintética de cada uma delas, e sugerir um exercício comparativo.

\section{A Venezuela entre a "V República" e 0 "socialismo do século XXI"}

O processo refundador venezuelano, iniciado a partir da eleição para presidente de Hugo Chávez em 1998, apresenta desde então transformações, de forma alguma unidirecionais, com indefinições, quebras e transições mais sutis. Transformações, no entanto, que levaram de um processo de refundação do Estado, da República (fundando a "V

das novas constituições; bem como os diversos referendos revogatórios levados a cabo especialmente na Venezuela e na Bolívia, incluindo os dos próprios presidentes - no primeiro por iniciativa popular (da oposição), no segundo do próprio presidente -, em ambos os casos vencidos pelos mandatários. Também não vou tratar das transformações introduzidas nos mecanismos de representação, estendendo-os na forma de aumento da representação de gênero e indígena, bem como a estendendo a espaços onde anteriormente não existia - como o Poder Judiciário. 
República"), a uma tentativa de lançamento de uma transição mais profunda a uma nova sociedade e economia, (in) definidas de forma geral como "socialismo do século XXI", "um conceito vago associado a valores como a solidariedade, a fraternidade, a justiça, a liberdade e a igualdade" (LÓPEZ MAYA, 2008, p.69). Segundo Chávez, ele deveria recorrer ao cristianismo "autêntico", ao marxismo e ao bolivarianismo, articulando ideais como a moral, a ética, o nacionalismo, a democracia. Além disso, deveria ser eminentemente social, não econômico, o que o permitiria promover a propriedade privada "honesta", baseada em relações de trabalho "harmoniosas" (apud MARINGONI, 2009, p.174-175).

Nessa tentativa inconclusa de transição, ver-se-á que as noções de democracia "oficiais" também vivenciaram transformações significativas. Chávez que, desde os anos 1970, fomentava movimentos militares que visavam ao golpe de Estado - finalmente tentado sem sucesso em 1992 -, após ser anistiado e deixar a prisão, em 1994, defendeu o boicote às eleições. Ele deixou essa posição para aceitar a participação institucional menos de dois anos antes de sua eleição para presidente, e o fez de maneira até certo ponto "instrumental", na medida em que considerava "podre" e "enganosa" a democracia vigente em seu país. No entanto, ao atacar as instituições, ele propôs substituí-las por novas instituições democráticas.

2 "Em seus discursos atuais Chávez se refere a amplas influências políticas que vão desde Jesus, passando por Bolívar, Gramsci, Trotsky e Mao, chegando até Antonio Negri. O que à primeira vista pode parecer um coquetel ideológico absurdo na verdade representa a amplitude de influências políticas, sociais, culturais e até religiosas que nutrem [o movimento]. Chávez não assume tanto o papel de dar uma linha política, mas sim de abrir um marco político" (AZZELLINI, 2007, s. p.). 
Nos primeiros anos de governo, o projeto transformador liderado por Chávez apontava para uma valorização da participação. Essa valorização se expressava na fórmula da "democracia protagônica". Nesse ponto, as formas clássicas de representação deveriam ser mantidas, e são reconhecidas na nova Constituição. Tudo isso, malgrado a desvalorização que vez por outra se dirigia a ela desde o discurso oficial especialmente no que tange às instituições anteriores (da "IV República") e aos partidos de forma geral. ${ }^{3}$ No entanto, progressivamente, pode-se notar uma transformação dessa combinação entre formas de representação e participação, na direção de uma valorização maior da segunda, porém agora concebida de forma ligeiramente distinta. Isso pode ser traduzido na fórmula lançada desde 2006 do "poder popular" e de uma "democracia revolucionária e socialista", em meio à construção de uma "nova geometria do poder" - tudo isso articulado com o avanço das propostas na direção de um "socialismo do século XXI". Chávez então manifestou "mais claramente tendências a enterrar as instituições liberais” (LÓPEZ MAYA, 2008, p.69). Note-se que não se trata apenas de uma mudança na correlação entre participação e representação. Buscou-se uma mudança na natureza da concepção de participação, e das instituições desenhadas para sua efetivação. Nesse sentido, o elemento principal a ser levado em conta é a constituição dos Conselhos Comunais (CC), organizados a partir de certo número de famílias estabelecidas num âmbito

3 Note-se que o chavismo não apenas voltou seus ataques à "partidocracia" e aos "partidos tradicionais", mas igualmente levou anos para aceitar a ideia de se organizar num partido próprio (o Partido Socialista Unido da Venezuela, PSUV), bem como retirou do texto constitucional as referências às organizações partidárias. 
espacial local. Estes foram fomentados pelo regime especialmente a partir de 2006, como mecanismo preferencial de participação popular no desenho e implantação de políticas públicas. A Lei Orgânica dos Conselhos Comunais (de 2006, modificada em 2009) os define como:

instâncias de participação, articulação e integração entre os cidadãos, cidadãs e as diversas organizações comunitárias, movimentos sociais e populares, que permitem ao povo organizado exercer o governo comunitário e a gestão direta das políticas públicas e projetos orientados a responder às necessidades, potencialidades e aspirações das comunidades, na construção do novo modelo de sociedade socialista de igualdade, equidade e justiça social (ASAMBLEA NACIONAL DE LA REPÚBLICA BOLIVARIANA DE VENEZUELA, 2009).

Os CC se estruturam a partir da realização periódica de assembleias locais, que estabelecem comitês dirigentes com distintas funções. Dedicam-se prioritariamente à articulação de organizações de base existentes e ao fomento de novas; elaboração de um plano de trabalho; controladoria social sobre projetos públicos; e mesmo ao eventual desenvolvimento e gestão de projetos públicos. Conjuntamente, são responsáveis pela participação direta nas decisões e na implantação de políticas públicas a nível barrial e comunitário, e relacionam-se diretamente com o Executivo nacional (JUNGEMANN, 2008), atualmente através do Ministério do Poder Popular para as Comunas e Proteção Social. Este capacita e forma seus 
dirigentes, define parâmetros para seu funcionamento, avalia suas atividades, fomenta novos CC, e disponibiliza os recursos financeiros e técnicos necessários para a realização de seus projetos - exercendo provavelmente um razoável poder sobre eles. ${ }^{4}$ Recentemente, tem havido um esforço para que os CC formem instâncias superiores, denominadas "comunas", que assumiriam o autogoverno em espaços maiores e potencialmente assumiriam um caráter ainda mais marcado de poder alternativo e sobreposto às instituições de representação municipais.

Ao longo desse processo de transformações, um dado a ser considerado é a significativa extensão ideológica apresentada pelo processo refundador venezuelano, que se ampara desde o início em construções ideológico-identitárias difusas como o "bolivarianismo" e o "chavismo" - associados, mas com fronteiras distintas (SEABRA; PEREIRA DA SILVA, 2011) - e mais tarde, o "socialismo do século XXI". Da mesma maneira, os conceitos de democracia do processo apresentam aspectos difusos e cambiantes. Mas de forma genérica, nota-se certa inflexão (inconclusa) de uma participação em órgãos de planificação a uma tentativa de construção do poder popular, associado à cúpula estatal. Uma constante seguiu sendo a

4 Segundo García-Guadilla (2009), os CC são criados de "cima para baixo"; dependem dos recursos oficiais; prestam-se mais à execução de benfeitorias locais que ao debate ou ao desenho de políticas públicas mais gerais; dificilmente reúnem setores sociais plurais, além de possuir dificuldades de articulação entre eles; e são acionados pelo regime como apoios em momentos eleitorais. Conclui que "enquanto os objetivos e o discurso presidencial falam de apoderamento, transformação e democratização, as práticas observadas apontam na direção do clientelismo, cooptação, centralização e exclusão devido à polarização política” (p.320-321). 
realização de atos plebiscitários, oscilando entre a expressão da vontade popular e a legitimação do processo e de seu líder máximo. Ou seja, como fortalecimento efetivo da democracia ou como manutenção e mesmo aprofundamento das capacidades do Executivo.

\section{A Bolívia entre o "viver bem" e o "(neo) desenvolvimentismo"}

O caso boliviano é distinto do venezuelano, em suas concepções democráticas e desenvolvimento posterior. $\mathrm{O}$ Movimento ao Socialismo (MAS), seu líder e as forças sociais que eles agregam desde o processo de construção contra-hegemônica que os levou ao poder, apresentam, no entanto, uma característica comum ao desenvolvimento chavista: a pluralidade ideológico-identitária, que se traduz na complexidade do projeto e igualmente de sua visão de democracia. Como desenvolvi em trabalho anterior (PEREIRA DA SILVA, 2009), o MAS se equilibra entre correntes indigenistas, nacional-populares e de esquerda "tradicional". Assim se desenvolveu seu governo nos primeiros anos, e se construiu uma concepção plural de democracia, que preservou os elementos representativos (ainda que não em chave precisamente liberal), fomentou a participação e defendeu valores de uma "democracia comunitária" associada a ideias de coletivismo, consenso mediante debate, assembleísmo e cooperativismo - que deveria fazer-se presente nas organizações populares e movimentos sociais, nos espaços locais de autonomia territorial, e ser reconhecida pelo Estado plurinacional. A inspiração aqui vem da experiência dos sindicatos camponeses/ 
indígenas 5 , que constituíram o principal núcleo fundador e dinamizador do MAS e do processo contra-hegemônico ora constituindo-se em hegemônico. A ideia se associa de forma geral à concepção de um "bem viver" andino, que seria baseado na "complementaridade de conhecimentos", num estado de vida integrado à natureza e baseado numa visão cosmológica de paridade do homem com ela, que levaria a uma sociedade de justiça social e ambiental (TAMBURINI MALLONI, 2011).

Sugiro que, nessa complexa equação, as correntes e propostas nacional-populares vêm se impondo. Com isso, vem se manifestando crescentemente um projeto (neo)desenvolvimentista, que curiosamente se associa a interesses perfeitamente materialistas e "ocidentalistas" do principal movimento indigenista associado ao governo, dos cocaleiros, que exigem conexões com os grandes centros urbanos, escoamentos para sua produção e colonização de novas terras. E que encontra igualmente afinidades ideológicas com projetos de referentes da esquerda, como o vice-presidente Álvaro García Linera e seu "capitalismo andino-amazônico."6

5 Estruturas sindicais "ocidentais" (e o próprio nome "sindicato") imbricadas com estruturas comunais originárias. Os sindicatos, mais que instrumentos reivindicativos e de socialização, organizam a vida comunitária dos indivíduos e famílias que os integram, repartindo terras, aplicando justiça comunitária, organizando trabalho voluntário, comercializando produtos cultivados, entre outras funções.

6 Este advoga ou prevê uma etapa de desenvolvimento capitalista de Estado, valorizando o comunitarismo, a pequena produção e a diversidade étnico-cultural, antes do socialismo de novo tipo ("socialismo comunitário") baseado nas tradições comunitárias originárias (GARCÍA LINERA, 2010). 
Agora que se manifestam enfrentamentos internos entre setores camponeses indígenas e urbanos do Altiplano de um lado, com povos indígenas originalmente do Oriente por outro ${ }^{7}$, coloca-se no centro do processo uma tensão entre nacionalização e desenvolvimento industrial estatalmente orientado, em contraposição a valores de preservação da natureza e do "viver bem”. Para García Linera (2011), esse dilema seria desnecessário, na medida em que a pretensa "industrialização popular" que ora começa deve respeitar o meio ambiente, sendo essencialmente distinta da exploração da natureza do modo capitalista. Só o tempo dirá se essa formulação apresenta alguma sustentação na realidade. Mas o ponto a ser destacado é que o (neo)desenvolvimentismo parece estar se impondo como denominador comum entre setores indigenistas, de esquerda e nacional-populares no governo - com predominância desses últimos.

O novo Estado boliviano apresentaria características de "democracia comunitária", seria marcado pelo protagonismo dos movimentos sociais, mas manteria os elementos

7 Dos quais, as disputas ocorridas, em 2011, em torno da construção (finalmente cancelada pelo governo central) de uma estrada cruzando o Território Indígena e Parque Nacional Isidoro Sécure (TIPNIS) foi apenas o evento mais dramático. Para Vadillo Pinto (2011), as diferenças entre aimaras e quéchuas que buscam terras para assentamentos nas regiôes do Oriente e amazônicas, e povos indígenas das terras baixas que demandam o reconhecimento oficial dos seus territórios como "espaços de vida" e não de produção agrícola tendem a se aprofundar. Tais diferenças não seriam de origem étnica, cultural ou geográfica, e sim econômicas e classistas. 
representativos. Dessa forma, estaria se constituindo uma "democracia intercultural", sustentada

na existência das nações e povos indígena originário camponeses ${ }^{8} \mathrm{e}$ das comunidades interculturais e afrobolivianas (...) com diferentes formas de deliberação democrática, distintos critérios de representação política e o reconhecimento de direitos individuais e coletivos, (...) [e] baseada na complementaridade da democracia direta e participativa, democracia representativa e democracia comunitária" (Lei do Regime Eleitoral, apud COLPARI, 2011, p. 5)'.

Nesse sentido, para além das consultas recorrentes e relativamente informais entre o governo e os movimentos sociais, especialmente em seus primeiros anos, e dos referendos e revocatórias de mandato, essa complementaridade entre distintas formas de democracia começou a tomar forma a partir da promulgação de duas leis em meados de 2010, a Lei Marco de Autonomias e Descentralização "Andrés Ibáñez" e a Lei do Regime Eleitoral. No sentido da descentralização, foram

8 Esta foi a fórmula oficial encontrada para expressar na nova legislação boliviana a pluralidade identitária contida nos indivíduos, grupos sociais e movimentos que se compreendem ao mesmo tempo como indígenas ("povos originários") e camponeses.

9 Remeto à tese de Boaventura de Sousa Santos acerca da "demodiversidade" (na linha da "ecologia de saberes" proposta pelo autor) e da fusão entre democracia representativa e participativa/direta na direção de uma "democracia de alta intensidade" (SANTOS, 2010; SANTOS, AVRITZER, 2003). 
definidos quatro níveis administrativos e deliberativos além do nacional: o departamental, o municipal, o regional e o indígena. Além disso, foram constituídos órgãos consultivos, de transparência e controle estatal, através do Ministério de Transparência e Luta contra a Corrupção. Nele, articulam-se atividades em quatro eixos: aprofundamento da participação cidadã; transparência na gestão pública e direito de acesso à informação; eliminação da corrupção; e fortalecimento e coordenação institucional. Espera-se fomentar esses valores a partir de atividades de audiências públicas, capacitações e prestação de contas, com a participação de organizações sociais e originárias e de funcionários públicos, no âmbito dos distintos órgãos governamentais nacionais (e eventualmente em outros níveis) ${ }^{10}$.

\section{O Equador e os dilemas da "revolução cidadã"}

A refundação levada a cabo no Equador por Rafael Correa e seu movimento Pátria Altiva e Soberana (PAÍS) está num ponto de desenvolvimento preliminar em relação aos casos anteriores, e parece mais moderada que seus congêneres, basicamente por duas razões: o perfil do líder e de seu movimento (o primeiro mais moderado e desenvolvimentista, o segundo mais difuso e "cidadão"); e o fato de se constituir descolado movimento indigenista, que lhe faz oposição. Aqui também

10 Ainda é cedo para avaliar a natureza dessa interação. No entanto, na medida em que é o Estado que define a agenda, a legitimidade dos participantes e os espaços de abertura, em boa medida essa participação estaria organizada e controlada desde o Estado, "de cima para baixo". 
se dedica especial atenção às modalidades de democracia participativa e direta, e foram desenvolvidos mecanismos plebiscitários e de consulta e apoderamento popular. Correa e seu movimento assumiram uma modalidade de governo "decisionista", um esforço de "campanha permanente" associado "a uma variedade extrema de presidência plebiscitária” (CONAGHAN; DE LA TORRE, 2008, p.269). No entanto, as modalidades de democracia representativa não chegaram a ser contestadas.

A construção ideológica do movimento apresenta características de um "socialismo cristão", e propostas que oscilam entre o (neo)desenvolvimentismo (um "desenvolvimento equitativo") e elementos ecológicos e "pós-materialistas" (quando chega a se referir ao "viver bem"). No entanto, há evidente predominância do primeiro: "não nos enganemos, necessitamos prosperidade material, capacidade de acumulação, produzir mais do que consumimos" (CORREA, 2010, [s.p.]). Eventualmente se referiu à passagem de um Estado "burguês" a um Estado "popular", bem como ao "socialismo do século XXI", de forma ainda mais imprecisa que no caso venezuelano: "sem pretender ter todas as respostas, é ao menos nossa resposta frente a sistemas excludentes, especulativos, responsáveis de haver conduzido a humanidade a um beco sem saída de crise civilizatória e de destruição do meio ambiente" (CORREA, 2010, [s.p.]).

Nesse sentido, os experimentos democráticos equatorianos seguem a mesma direção dos apresentados na Bolívia: organismos deliberativos e consultivos associados ao aparato estatal nacional, através de uma instituição que integra um dos novos poderes estatais, a função de Transparência 
e Controle Social. Trata-se do Conselho de Participação Cidadã e Controle Social (CPCCS), que agrega e fomenta diversos projetos e instituições voltadas à participação e desenvolvimento de projetos; à accountability vertical (fiscalização, transparência, prestação de contas); e à transparência e controle da corrupção. ${ }^{11}$

O CPCCS se estrutura desde uma direção formada por conselheiros que se candidatam e são escolhidos mediante concurso público ${ }^{12}$, passando por secretarias executivas, e chegando às iniciativas de participação (Cabildos Populares e Redes Cidadãs) e controle social (Controladorias e Observatórios Cidadãos). Desses organismos, os primeiros são os que permitiriam efetivamente maior deliberação popular - ainda que preservem, também, valores e funções de fomento da transparência, rendição de contas e conscientização popular. Em especial, as Redes Cidadãs, articulações

11 Como versa o Artigo 204 da nova Constituição: "A Função de Transparência e Controle Social promoverá e impulsionará o controle das entidades e organismos do setor público, e das pessoas naturais ou jurídicas do setor privado que prestem serviços ou desenvolvam atividades de interesse público, para que os realizem com responsabilidade, transparência e equidade; fomentará e incentivará a participação cidadã; protegerá o exercício e cumprimento dos direitos; e prevenirá e combaterá a corrupção" (REPÚBLICA DEL ECUADOR, 2008). Além do CPCCS, a Função de Transparência e Controle Social também é constituída por outros órgãos, como a Defensoria Geral do Povo, a Controladoria Geral do Estado e as Superintendências de Bancos, Companhias e Telecomunicações.

12 Podem se candidatar representantes de organizações sociais ou cidadãos comuns, selecionados por mérito e oposição, com espaço previsto no processo para o controle e impugnação por parte da cidadania. Os requisitos são apenas a maioridade e não estar filiado a nenhum partido (PERNASETTI, 2010). 
de membros da sociedade civil e cidadãos comuns a nível local, regional e nacional, que esperam funcionar como articulação e legitimação nas relações entre Estado e sociedade. Deve-se destacar, também, que o Estado promove outros espaços de participação, tais como: mesas de diálogo, assembleias locais, a criação de "cadeiras vazias" em órgãos governamentais para serem preenchidas por membros da sociedade civil, além de garantir a participação de cidadãos no Conselho Nacional de Planejamento, responsável pelo Plano Nacional de Desenvolvimento.

\section{Considerações finais}

Os três governos refundadores analisados nessas páginas apresentam concepções "heterodoxas" de democracia (críticas à concepção liberal de democracia eminentemente representativa e procedimental), que associam à representação diversas concepções de participação, deliberação direta, comunitarismo e poder popular. Pode-se entender a democracia como uma pluralidade de formas de expressão que permite diversas combinações e estruturações, mediante atuação direta ou deliberação a partir de representantes. Nos países estudados, sugiro que há uma combinação entre as instituições da democracia representativa, novas formas de participação e fenômenos mais próximos de uma "democracia plebiscitária". Em certo sentido, poderiam constituir expressões de "demodiversidade” (SANTOS, 2010; SANTOS, AVRITZER, 2003), mas ao mesmo tempo das dificuldades contidas em sua realização. Por um lado, a democracia representativa é criticada nesses processos de refundação, geralmente associada à "velha 
política", aos "partidos tradicionais", à corrupção e dominação que os refundadores pretendem superar. Por outro, a partir dos novos Estados e da sociedade organizada, surgem expressões e novas institucionalidades de participação e deliberação direta, que na prática convivem até aqui com a preservação dos mecanismos de representação.

Além disso, os diferentes processos de refundação lançaram mão de alguns mecanismos de democracia direta semelhantes, como o plebiscito, o referendo e a revogação de mandato. Quanto aos novos espaços de participação, passam principalmente por mecanismos de controle e rendição de contas, através da instituição nos três países de novos poderes direcionados a isso, transformando a lógica liberal clássica de divisão do aparato estatal em três poderes ${ }^{13}$; e de cogestão, aí incluídos o desenho de políticas públicas e elaboração de planos nacionais na Bolívia e no Equador, e a execução de obras, programas sociais, prestação de serviços e mesmo gestão de empresas públicas na Venezuela.

No entanto, começa a notar-se aqui certa diferença, especialmente a partir das elaboraçóes venezuelanas em torno do "poder popular" e do "socialismo do século XXI", bem como da instituição dos CC. Ainda que de forma inconclusa, o caso venezuelano parece apresentar desde então ecos de uma transformação mais profunda das concepções democráticas e desenhos institucionais, na qual um novo poder (micro) local alternativo começa a assumir funções de prestação

13 A Função de Controle, Defesa da Sociedade e do Estado na Bolívia, a Função de Transparência e Controle Social no Equador, e o Poder Cidadão na Venezuela. 
de serviços e funções públicas - enquanto na Bolívia e no Equador seguem atuando prioritariamente como espaços de consulta, deliberação, pressão e accountability vertical. Resta saber se esse novo espaço de poder comunal preserva autonomia em relação ao poder central, e se tem capacidade decisória sobre o desenho de políticas e projetos nacionais - ou apenas sobre atividades muito específicas a nível local ou de bairros.

\section{Referências}

ASAMBLEA NACIONAL DE LA REPÚBLICA
BOLIVARIANA DE VENEZUELA. Ley Orgánica de los Consejos Comunales. Caracas: [s. n.], 2009.

AZZELLINI, D. La Revolución Bolivariana: "o inventamos o erramos". Claves para leer el proceso de transformación social venezolano. Herramienta, n. 36, 2007.

COLPARI, O. La nueva participación ciudadana en Ecuador y Bolivia. ¿Resultado de la lucha del movimiento indígena-campesino? Nómadas. Revista Crítica de Ciencias Sociales y Jurídicas, n. especial América Latina, 2011.

CONAGHAN, C.; DE LA TORRE, C. The permanent campaign of Rafael Correa: making Ecuador's plebiscitary presidency. Press/Politics, v. 13, n. 3, 2008. 
CORREA, Rafael. Discurso. Congreso de la Confederación Latinoamericana de Organizaciones del Campo (CLOC) Vía Campesina. Quito, 2010.

ESTADO PLURINACIONAL DE BOLIVIA.

Constitución Política del Estado. S.l.: Gaceta Oficial de Bolivia, 2009.

GARCÍA-GUADILLA, M. P. La praxis de los Consejos Comunales. ¿Poder popular o instancia clientelar? In: Ayala, M. Quintero, P. (orgs.). Diez años de revolución en Venezuela. Historia, balance y perspectivas (1999-2009). Ituzaingó: Maipue, 2009.

GARCÍA LINERA, Álvaro. Las tensiones creativas de la revolución. La quinta fase del proceso de cambio. La Paz: Vicepresidencia del Estado Plurinacional - Presidencia de la Asamblea Legislativa Plurinacional, 2011.

. El socialismo comunitario: un aporte de Bolivia al mundo. Entrevista al Vicepresidente del Estado Plurinacional Ciudadano Álvaro García Linera. Revista de Análisis: reflexiones sobre la coyuntura, ano 3, n. 5, 2010.

JUNGEMANN, B. Organizaciones sociales y anclaje territorial. Escenarios y componentes de la transformación socioterritorial y local en Venezuela. Cuadernos del CENDES, v. 25, n. 67, 2008. 
LÓPEZ MAYA, M. Venezuela: Hugo Chávez y el bolivarianismo. Revista Venezolana de Economía y Ciencias Sociales, v. 14, n. 3, 2008.

MARINGONI, Gilberto. A revolução venezuelana. São Paulo: UNESP, 2009.

PEREIRA DA SILVA, Fabricio. Vitórias na crise: trajetórias das esquerdas latino-americanas contemporâneas. Rio de Janeiro: Ponteio, 2011.

. Equilíbrios precários: a trajetória do Movimento ao Socialismo e seus dilemas. In: Domingues, J. M. et al. (orgs.). A Bolívia no espelho do futuro. Belo Horizonte: UFMG; Rio de Janeiro: IUPERJ.

PERNASETTI, F. Agendas de reforma e aprofundamento da democracia na América do Sul: um primeiro olhar sobre o Conselho de Participação Cidadã e Controle Social do Equador. Observador On-line, v. 5, n. 7, 2010.

REPÚBLICA BOLIVIARIANA DE VENEZUELA. Constitución de la República Bolivariana de Venezuela. S.l.: Gaceta Oficial de la República Bolivariana de Venezuela, 1999.

REPÚBLICA DEL ECUADOR. Constitución de la República del Ecuador. S.l.: Registro Oficial, 2008. 
SEABRA, R. L.; PEREIRA DA SILVA, F. Sugerencias teóricas para un abordaje de la vía bolivariana. II Congreso Historia Inmediata, Maracaibo, 2011.

SANTOS, B. S. Para una democracia de alta intensidad. Ecuador Debate, n. 80, 2010.

. AVRITZER, L. Para ampliar o cânone democrático. In: Santos, B. S. (org.). Democratizar a democracia. Porto: Afrontamento, 2003.

TAMBURINI MALLONI, L. El movimiento indígena originario. Su rol en la construcción de la sociedad y el Estado boliviano. In: OPN - UARGM. El Estado Plurinacional Autonómico. Alcances y límites. Santa Cruz: OPN UARGM, FBDM, UARGM, 2011.

VADILLO PINTO, A. El movimiento indígena originario. Su rol en la sociedad y el Estado. In: OPN - UARGM. El Estado Plurinacional Autonómico. Alcances y límites. Santa Cruz: OPN - UARGM, FBDM, 2011. 